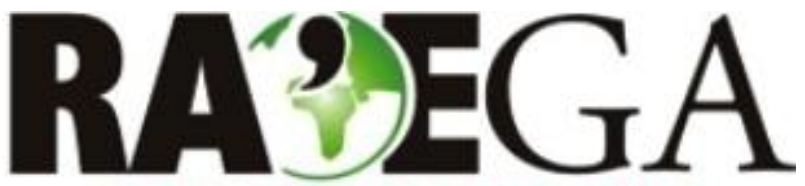

O ESPACYO GEOGRÁFICO EM ANÁLISE

\title{
A PRÁXIS DA CULTURA UCRANIANA NO ESPAÇO URBANO DE RONCADOR (PR), BRASIL: ANÁLISE DAS CATEGORIAS FORMA, FUNÇÃO, ESTRUTURA E PROCESSO
}

\section{THE PRAXIS OF UKRAINIAN CULTURE IN THE URBAN SPACE OF RONCADOR (PR), BRASIL: ANALYSIS OF THE CATEGORIES FORM, FUNCTION, STRUCTURE AND PROCESS}

\author{
Marcos Clair Bovo \\ Professor da Universidade Estadual do Paraná (UNESPAR) \\ Programa de Pós-Graduação Interdisciplinar Sociedade e Desenvolvimento (PPGSeD) \\ Campo Mourão, $P R$ \\ e-mail:mcbovo@yahoo.com \\ Elaine Cristina Zavadovski Kalinovski \\ Mestranda em Geografia pela Universidade Estadual de Maringá (UEM) \\ Maringá, $P R$ \\ e-mail: elaine_kalinovski@hotmail.com \\ Ricardo Luiz Töws \\ Professor do Intituto Federal de Educação, Ciência e Tecnologia do Paraná (IFPR) \\ Londrina, $P R$ \\ e-mail: ricardotows@gmail.com
}

Recebido em: 29/05/2013

Aceito em: 14/05/2014

\section{Resumo}

O estudo versa sobre a cultura ucraniana na imagem da cidade de Roncador (PR), destacando, nesse prisma, a contribuição do grupo étnico no processo de colonização e formação do núcleo urbano. O aporte teórico que sustenta a análise tem como base as categorias analíticas propostas por Milton Santos, isto é, forma, função, estrutura e processo, as quais são fundamentais para a compreensão da produção do espaço, que, nesse caso, teve como agentes sociais a população de ascendência ucraniana. No âmbito deste contexto, atentamos, sobretudo, para o entendimento dos aspectos inerentes à cultura material, tendo como enfoque a abordagem das formas arquitetônicas e o padrão das edificações fixadas pela etnia ucraniana no decurso da colonização do município. Para tanto, ressaltamos o uso da História Oral como principal recurso metodológico empregado na presente pesquisa, uma vez que permite o registro e arquivamento de informações disponibilizadas pelas fontes orais, perfazendo, desse modo, um importante documento histórico passível de utilização para a investigação científica. Nesse sentido, a partir dos referenciais teórico, empírico e técnico, evidenciamos que as formas culturais 
impressas pelo grupo ucraíno no espaço urbano de Roncador não sucumbiram frente ao processo de modernização da vida urbana, compondo no atual momento histórico resquícios das formas tradicionais, herdadas do passado.

Palavras-chave: Colonização, grupo étnico, história oral.

\begin{abstract}
This study deals with the Ukrainian culture in the image of Roncador (PR), highlighting, in this prism, the contribution of the ethnic group in the process of colonization and formation of the urban core. The theoretical source that supports the analysis is based on the analytical categories proposed by Milton Santos, namely, form, function, structure and process, which are fundamental for the comprehension of the space production that, in this case, had for social agents the population of Ukrainian ascendancy. In this context, we aimed mainly at understanding the aspects which are inherent to the material culture, focusing the approach of the architectural forms and the pattern of buildings set by the Ukrainian ethnicity along the city's colonization. For that, we highlighted the use of Oral History as the main methodological resource applied in this research, since it allows the registration and filing of information provided by oral sources, and thus composing an important historical document that can be used for scientific research. In this sense, from the theoretical, empiric and technical sources, we evince that the cultural forms printed by the Ukrainian group in the urban space of Roncador did not succumb in face of the modernization process of urban life, composing, in present History, remnants from the traditional forms, inherited from the past.
\end{abstract}

Keywords: Colonization, ethnic group, oral history.

\title{
INTRODUÇÃO
}

O presente artigo tem como temática o estudo da inserção e o processo de permanência dos traços da cultura ucraniana na área urbana do município de Roncador (PR). Para essa análise, destacamos as formas da cultura ucraniana, fixadas durante o processo de colonização, e que permanecem como rugosidades, termo este aqui entendido como os resquícios das formas culturais herdadas do passado e que não mais se enquadram ao atual modelo de sociedade capitalista contemporânea, mas que têm demonstrado resistência ao processo de modernização e consolidação de novas estruturas. Destarte, a nossa problemática visa entender como a cultura ucraniana sobrevive e resiste ao processo de urbanização de Roncador, frente à expansão do modo de produção capitalista dominante que traz consigo uma urbanização que visa aos interesses do capital e não levam em consideração as formas tradicionais da cultura local, forçando-as ao 
desaparecimento, o que denota, assim, o descomprometimento do poder público municipal com as questões culturais que envolvem o ambiente urbano.

Entrementes, perpassa aqui a preocupação em chamar a atenção do poder público municipal, da comunidade ucraniana interessada, para a questão da preservação e irradiação de seus signos identitários e traços culturais no centro urbano de Roncador, estando sempre presentes as marcas dessa cultura na imagem da cidade, mantendo, desta forma, a sua identidade, além de constituir um importante potencial para o desenvolvimento do turismo no município, divulgando a cultura ucraniana como um atrativo cultural e religioso. Nesse sentido, a cultura ucraniana, impregnada na paisagem da cidade, constitui-se em um diferencial importante para o município, devendo ser assegurada a sua preservação, tanto pelos setores sociais quanto por aqueles setores que cuidam do planejamento urbano, assegurando a manutenção de sua identidade e revelando o seu potencial para o desenvolvimento local.

Vale ressaltar que, semelhante abordagem já fora retratada em trabalho anterior por Kalinovski, Bovo e Töws (2011), que apresentaram algumas considerações preliminares e parciais sobre a permanência da cultura ucraniana no contexto urbano de Roncador, destacando que no presente estudo as análises foram aprofundadas e ampliadas, expondo resultados inéditos até então não contemplados pelos autores.

Por ora, salientamos a relevância e pertinência científica do estudo, haja vista a discussão e contribuição teórico-conceitual a respeito das categorias de análise que envolve a nossa temática, bem como pretende ser um referencial importante sobre a região estudada, no que concerne ao entendimento de seu processo de colonização, influência étnica e cultural, além de suscitar o debate acerca da preservação do patrimônio histórico-arquitetônico e urbano dessa organização espacial caracterizada pela presença da comunidade ucraniana.

Por sua vez, é importante ressaltar que, para o desenvolvimento da pesquisa, utilizamos como procedimentos metodológicos os referenciais teórico, empírico e técnico, sendo que a principal ferramenta metodológica empírica consistiu na realização de entrevistas com as fontes orais, isto é, a partir do depoimento dos próprios descendentes de ucranianos, que participaram diretamente 
A PRÁXIS DA CULTURA UCRANIANA NO ESPAÇO URBANO DE RONCADOR (PR), BRASIL: ANÁLISE DAS CATEGORIAS FORMA, FUNÇÃO, ESTRUTURA E PROCESSO

do processo de colonização e urbanização do município de Roncador, ou que tiveram as suas famílias envolvidas no processo, o que nos possibilitou preencher as lacunas sobre a história do município, haja vista que não há documentos escritos que contemplem o processo de colonização e formação do espaço urbano da área em estudo.

Nesse sentido, Meihy (1996) ressalta que a História Oral se configura como uma ferramenta moderna empregada na elaboração de documentos, arquivamento de estudos atinentes à vida social das pessoas. Ela nos oferece um importante meio para se explorar e conhecer a vida social dos sujeitos entrevistados, o seu modo de vida, hábitos e costumes, além de revelar sentimentos e emoções, que são apreendidas no decorrer da fala dos entrevistados. Carneiro (2012) ao utilizar a História Oral como instrumento para o desenvolvimento e elaboração de sua pesquisa, aplicou essa metodologia para o entendimento das transformações ocorridas no município de Quinta do Sol durante as décadas de 1960, 1970, 1980 e 1990, obtendo resultados positivos e satisfatórios que corroboram a importância de se trabalhar com as fontes orais, que doravante, podem constituir documentos históricos de valor científico.

Sob essa ótica de análise e tendo em vista a utilização de técnicas metodológicas baseadas nas fontes orais, faz-se necessário esclarecer que, no transcorrer desta investigação, foram realizadas duas principais entrevistas, devidamente citadas e apresentadas neste excerto, contemplando antigos moradores do município de Roncador e pioneiros no processo de ocupação da área, os quais ainda mantêm costumes tradicionais e valores culturais que são legados da cultura ucraniana. Assim, de posse de um gravador, tais entrevistas foram gravadas e, posteriormente, realizamos a transcrição completa para a linguagem escrita, pois conforme assevera Meihy (1996), a história oral além de apresentar valor documental enquanto gravação, guardando em arquivos a modulação da voz e a situação da entrevista, requer, outrossim, sua versão para a linguagem escrita, a fim de facilitar o trânsito, reflexão e estudos.

Entretanto, vale notar que no momento da transcrição da linguagem oral para a linguagem escrita, buscamos manter a integridade da fala das pessoas de origem ucraniana por nós entrevistadas, para desse modo evitar a má interpretação 
de ideias ou um erro ainda mais grave, como o preconceito linguístico, se ousássemos interferir na maneira como essas pessoas falam, adequando-as às normas cultas da língua portuguesa. A esse respeito, Bagno (2004) contribui enfatizando que não existe erro de português sob a ótica científica, lembrando que todo falante nativo de uma língua é um falante plenamente competente dessa língua, de modo que ninguém comete erros ao falar sua própria língua materna. Para Thompson (1998) não há nada que substitua uma transcrição completa, sendo que a gramática e a ordem das palavras devem ser mantidas tal como foram pronunciadas.

Cabe a ressalva de que além das entrevistas realizadas neste trabalho, da mesma forma dispomos de um rico acervo com histórias narradas pelas fontes orais, cujos interlocutores são os descendentes de ucranianos residentes no município em questão. Esse acervo conta com um total de dez entrevistas, gravadas e filmadas, bem como um documental com sua transcrição integral para a forma escrita, cabendo enfatizar que as mesmas foram realizadas e arquivadas pelo projeto de pesquisa e extensão universitária, intitulado "A Geografia da Práxis e da Cultura Camponesa Ucraniana na Colonização da Mesorregião Centro Ocidental Paranaense", desenvolvido ao longo do ano de 2009 e 2010, no qual a segunda autora deste artigo foi parte integrante da equipe e, portanto, auxiliou nos trabalhos de levantamentos de dados e informações de crucial interesse para o estudo analítico proposto no projeto aludido e que vem a calhar com as discussões suscitadas na presente pesquisa, ao reportar à cultura ucraniana aliado ao processo de colonização e desenvolvimento regional.

Estudos congêneres, com enfoque aos aspectos culturais na geografia, são extremamente importantes nos dias atuais, pois de acordo com Claval (2002), caracterizam um retorno da dimensão cultural nas abordagens de cunho geográfico, que por algum tempo, ficaram a margem das preocupações e interesses dos geógrafos, porém, mais recentemente tem sido alvo das pesquisas na área, atrelado ao campo da geografia cultural. Nesse aspecto, tem-se a contribuição de inúmeros pesquisadores, dentre eles, pode-se destacar o renomado geógrafo francês Paul Claval (1999, 2002), principal expoente no desenvolvimento da Geografia Cultural, além de outros estudiosos, como Mello (2008) que se atentou a perspectiva 
A PRÁXIS DA CULTURA UCRANIANA NO ESPAÇO URBANO DE RONCADOR (PR), BRASIL: ANÁLISE DAS CATEGORIAS FORMA, FUNÇÃO, ESTRUTURA E PROCESSO

simbólica dos lugares, havendo um incremento nas pesquisas voltadas para as questões culturais.

\section{A FORMA, A FUNÇÃO, A ESTRUTURA E PROCESSO COMO CATEGORIAS DE ANÁLISE}

No que tange à discussão teórico-conceitual das categorias de análise que embasam a nossa pesquisa, cumpre ressaltar a contribuição do geógrafo Milton Santos (1985), que, em sua obra intitulada Espaço e Método, elenca quatro categorias como conceitos fundamentais para a compreensão da noção de produção do espaço. Assim sendo, é importante esclarecer que o referido autor entende o espaço como um produto social, uma instância da sociedade, ao mesmo título que a instância econômica e a instância cultural-ideológica, ponderando, desse modo, que a essência do espaço é social. Nesse sentido, Santos (1985, p. 1) aponta que "o espaço não pode ser apenas formado pelas coisas, os objetos geográficos, naturais e artificiais, cujo conjunto nos dá a Natureza. O espaço é tudo isso, mais a sociedade [...]". Em outro momento, Santos (2008a) assevera que o espaço é a materialidade, isto é, um conjunto de formas mais a vida que as anima, e deve ser considerado como uma totalidade, a exemplo da própria sociedade que Ihe dá vida.

Nesses termos, as categorias de análise forma, função, estrutura e processo constituem os alicerces que permitem a análise e interpretação da realidade espacial em totalidade, sendo que, para Santos (1985), forma é o aspecto visível de uma coisa. Refere-se, ademais, ao arranjo ordenado de objetos que compõem um padrão espacial, portanto diz respeito à materialização do espaço, aos objetos geográficos que foram produzidos em um momento do tempo histórico e são dirigidos pelo presente, não se devendo ignorar o seu passado, que está impregnado nas formas, uma vez que trazem as características do momento em que surgiram.

Por conseguinte, temos a função, que está diretamente relacionada com a forma. Conforme o autor, função é uma tarefa ou atividade esperada de uma forma, pessoa, instituição ou coisa. Assim, é importante dizer que a forma se reveste de função, isto é, desempenha alguma atividade, é provida de tarefa, o que lhe dá um sentido, um conteúdo social que é atribuído pelas relações sociais que se projetam no espaço. 
No que corresponde à estrutura, Santos (1985, p. 50) assinala que "Estrutura implica a inter-relação de todas as partes de um todo; o modo de organização ou construção". Sobre esse aspecto, é importante frisar que devemos levar em consideração a combinação entre forma, função e estrutura, cabendo a ressalva de que as mudanças da estrutura implicam, outrossim, mudanças da própria forma, visto que as estruturas podem criar novas formas mais adequada às novas funções que surgem no presente.

Não obstante, as novas funções não acarretam necessariamente 0 desaparecimento das formas velhas pelo aparecimento de novas formas, mas podem se adequar às formas antigas, criadas em instâncias passadas, que são, assim, readaptadas para desempenharem novas atividades. Há, desse modo, no dizer de Milton Santos (2008b, p. 77), uma "[...] readaptação de formas velhas para novas funções". Por conseguinte, a mudança das formas, devido à necessidade de novas funções exigidas pelas transformações estruturais da sociedade no decorrer do tempo, pode condicionar, igualmente, uma mudança estrutural, ou seja, "Alterações de velhas formas para adequação às novas funções são também uma mudança estrutural" (SANTOS, 2008b, p. 76). Logo, uma mudança estrutural pode se dar também pela mudança das formas.

Nessa mesma linha de raciocínio, convém elucidar a noção de processo. Segundo Santos (1985, p. 50), "Processo pode ser definido como uma ação contínua, desenvolvendo-se em direção a um resultado qualquer, implicando conceitos de tempo (continuidade) e mudança". Seguindo ainda as considerações do mesmo autor, "[...] o tempo (processo) é uma propriedade fundamental na relação entre forma, função e estrutura, pois é ele que indica o movimento do passado ao presente" (1985, p. 54). Há que se destacar que os processos criam funções e formas espaciais, isto é, criam atividades e suas materializações, tal como pondera Corrêa (1999), sendo assim uma categoria de grande proeminência para o entendimento da organização espacial e as mudanças que sucederam no decorrer de um processo histórico.

Portanto, cumpre salientar que os termos aqui elencados constituem uma base teórica e metodológica a partir da qual podemos discutir os fenômenos espaciais em totalidade. Todavia, Santos (1985) adverte que tais conceitos devem 
ser considerados em conjunto, para, dessa forma, podermos compreender o espaço social em qualquer tempo. Assim, segundo apontamentos realizados pelo autor, "[...] forma, função, processo e estrutura devem ser estudados concomitantemente e vistos na maneira como interagem para criar e moldar o espaço através do tempo" (1985, p. 52).

Ressaltamos que tais categorias de análise constituem o suporte analítico da temática que nos propomos a pesquisar, sendo essenciais para 0 nosso entendimento acerca da práxis da cultura ucraniana no espaço urbano de Roncador, que teve como agentes sociais da produção do espaço os imigrantes ucranianos e seus descendentes, que desempenharam papel relevante no processo de ocupação e desenvolvimento da área de estudo, inserindo as suas formas culturais no interior de uma estrutura caracterizada pelo processo de colonização. Dessa maneira, cumpre notar que nos ateremos na análise dos aspectos que envolvem a cultura material, buscando nas edificações e no espaço materializado as evidências da cultura ucraniana na área urbana de Roncador.

\section{DA COLONIZAÇÃO A FORMAÇÃO DO NÚCLEO URBANO: O CASO DA CULTURA UCRANIANA EM RONCADOR (PR)}

Este estudo tem como recorte espacial o município de Roncador (Figura 1), que está localizado na Mesorregião Centro Ocidental do Estado do Paraná, com suas terras pertencentes ao Terceiro Planalto ou Planalto de Guarapuava. Segundo o Instituto Paranaense de Desenvolvimento Econômico e Social - IPARDES (2011), o município está localizado entre as coordenadas geográficas de latitude 24우 36" 10 " $S$ e longitude $52^{\circ} 16^{\prime} 30^{\prime \prime} \mathrm{W}$, estando a uma altitude média de 762 metros, e faz limite com os municípios de Luiziana, Iretama, Palmital, Mato Rico, Nova Tebas e Nova Cantu. Conforme o censo realizado pelo Instituto Brasileiro de Geografia e Estatística - IBGE (2010), a população do município é de aproximadamente 11.537 habitantes. 


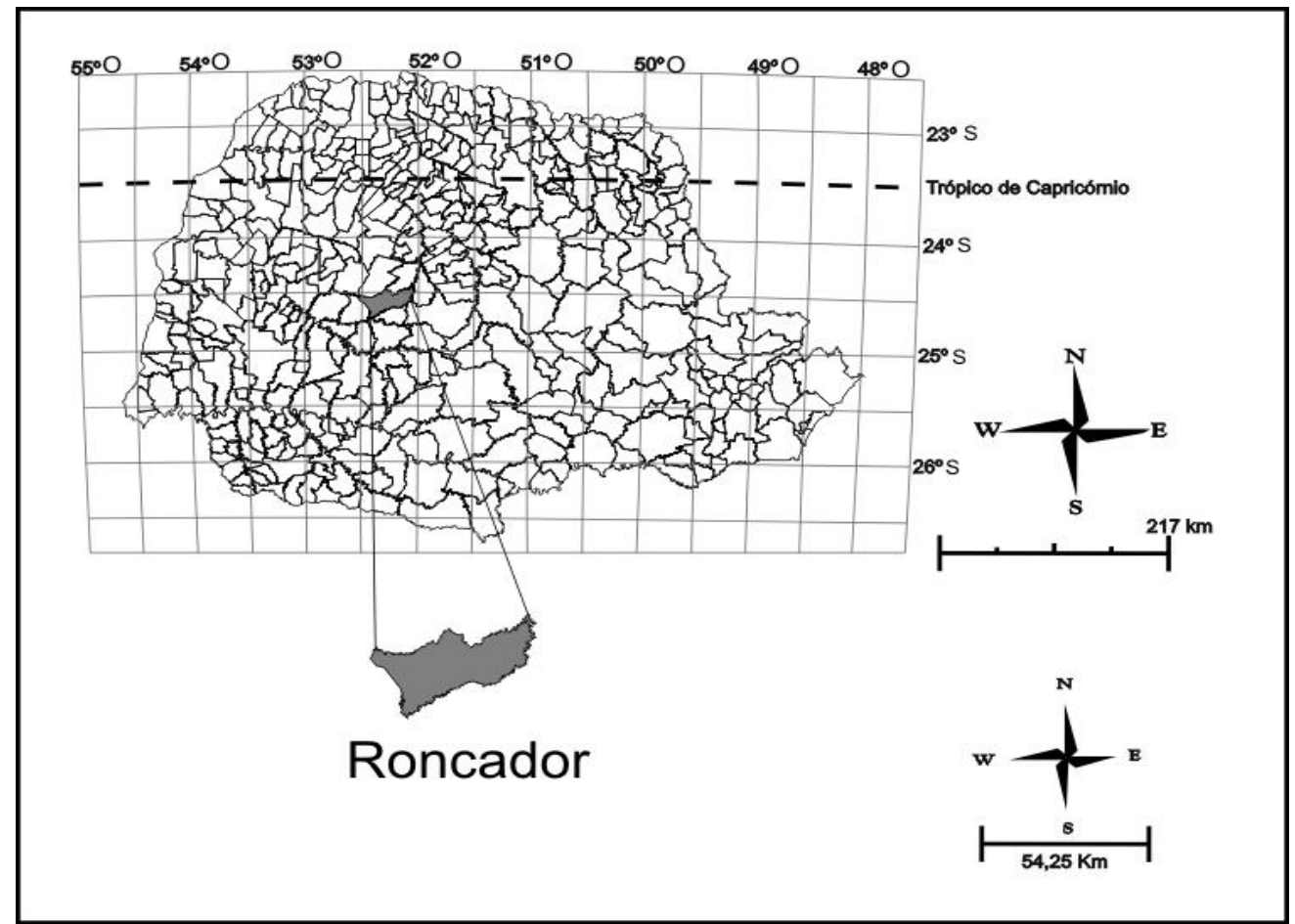

Figura 1: Localização do Município de Roncador no Estado do Paraná.

Fonte: da Base Cartográfica: adaptado do ITCG (2012). Org.: BUENO, Ricardo Henrique; KALINOVSKI, Elaine Cristina Zavadovski.

De acordo com o levantamento de dados realizado por Yurkiw (2009), Yurkiw e Haracenko (2012), o recorte temporal delimitado para o processo de colonização do município de Roncador compreende a fase que se estende desde os primórdios da década de 1920 até meados da década de 1970. Nessa mesma perspectiva de análise, concordamos com a autora ao dizer que o referido processo na região foi lento, no entanto contínuo, recebendo a chegada de diversos grupos étnicos, dos quais destacamos a presença do elemento da etnia ucraniana, que trouxeram consigo as suas tradições culturais e formas de vida para a região de Roncador. Diante disso, ressaltamos que as famílias de ascendência ucraniana singularizaram essa fração do espaço paranaense por suas práticas culturais, colaborando, dessa maneira, para o processo de identificação regional, haja vista as particularidades dessa cultura milenar que inseriu toda a sua materialidade e a imaterialidade simbólico-cultural nesse espaço, sendo hoje a principal influência étnica do município.

Nesse ínterim, cumpre evidenciar que os ucranianos e seus descendentes provenientes majoritariamente de centros difusores localizados ao Sul do Estado do 
A PRÁXIS DA CULTURA UCRANIANA NO ESPAÇO URBANO DE RONCADOR (PR), BRASIL: ANÁLISE DAS CATEGORIAS FORMA, FUNÇÃO, ESTRUTURA E PROCESSO

Paraná, especialmente da região de Prudentópolis e seus arredores, ocuparam e colonizaram as terras que correspondem ao atual município de Roncador, uma vez que, de acordo com o Periódico Suplemento do Jornal Prácia, intitulado "Missionário" (2006), a chegada desses imigrantes eslavos de origem europeia à localidade remonta à década de 1930 , período em que a colonização do município encontrava-se em sua fase inicial. Nesse sentido, o grupo que se direcionou para a área em estudo era formado tanto por imigrantes ucranianos, isto é, aqueles que vieram diretamente da Ucrânia, situada no leste europeu, quanto pelos descendentes que nasceram em solo brasileiro e sentiram a necessidade de construir um ambiente típico da Ucrânia na nova região, em decorrência do sentimento de nostalgia pelo país de origem, o amor à antiga pátria que deixaram para trás em busca de oportunidades e possibilidades de realizarem as suas manifestações culturais e religiosas em um novo país. Diante dessa conjuntura, logo que os ucranianos e seus descendentes chegaram à localidade de Roncador, deram início ao processo de ocupação da área, sendo que, para assegurar a preservação de seu legado cultural e a garantia da sobrevivência em uma região até então desconhecida por essas famílias, organizaram-se em agrupamentos, dando origem às colônias ucranianas na localidade.

A respeito do processo de colonização e das primeiras famílias que vieram para a área que compreende o atual município de Roncador, enfrentando enormes dificuldades, a senhora Elvira Slobodjan, de ascendência ucraniana, relata em entrevista que:

Os primeiro né, que nem meu sogro, quando eles chegaram aqui, os Slobodjan, Vogivoda, Olinek, era matão né, era sertão bruto, então eles pra entrá aqui, eles tinham que abrí picadão, que só passava carguero, sabe, de cavalo, porque nem carocinha num entrava né [...]. Então aqui a vida, do começo, foi muito difícil né, eles num tinham tabua pra fazê casa, eles faziam de vara, assim tirada no mato (SLOBODJAN, 2012).

O principal meio de sobrevivência dos colonos de descendência ucraniana no decurso do processo de ocupação da área a que se dedica nosso foco analítico consistia na agricultura de subsistência e na suinocultura, sendo que a produção era voltada, sobretudo, para o consumo interno das famílias. Sobre esse aspecto, temos 
a contribuição do depoimento concedido pelo padre Varcilio Basil Salkovski, neto de imigrantes ucranianos, que salienta: "Por muito tempo, que eu lembro, a gente plantava feijão, plantava arroz e milho com, digamos, as safras maiores. Outras culturas tal como o trigo ou algo assim, era somente para uso doméstico" (SALKOVSKI, 2011).

A partir das explanações realizadas pelo entrevistado acima citado, percebemos que os colonos de origem ucraniana, assim que se estabeleceram na nova região, procuraram imediatamente desenvolver alguma atividade econômica, atrelada principalmente aos cultivos agrícolas. Não obstante, o mesmo entrevistado esclarece que, além das atividades agrícolas desenvolvidas pelos descendentes de imigrantes ucranianos, também havia aqueles que se dedicavam ao comércio, o que contribuiu sobremaneira para 0 crescimento e desenvolvimento urbano de Roncador. Assim, assevera: "[...] tinha muitos ucranianos que também já trabalhavam no ramo do comércio em Roncador. Então, não somente os ucranianos trabalhavam no campo como eles foram um dos desbravadores do próprio Roncador, né" (SALKOVSKI, 2011).

Assim, cumpre notar que a comunidade ucraniana estabelecida em Roncador apresentou papel preponderante no desenvolvimento desta região, impulsionando, inclusive, a vinda de outros colonos para a área, o que foi de fundamental importância para o seu florescimento populacional e a consequente formação do núcleo urbano como resultado desse processo de ocupação. Segundo consta no Histórico de Roncador (1986), no início da década de 1950, a localidade inicia sua fase de desenvolvimento com o aumento da população, e passa a contar com diversos estabelecimentos comerciais, serrarias, posto de gasolina, farmácia e outros, o que Ihe conferiu sua elevação a Distrito. Sua emancipação política ocorreu no dia 25 de julho de 1960, através da Lei Estadual n.o 4.245, e, dessa forma, Roncador foi elevado à categoria de município, com território desmembrado do município de Campo Mourão, sendo que a sua instalação ocorreu no dia 05 de novembro de 1961 (FERREIRA, 2006).

Do mesmo modo, é importante salientar a contribuição da população de ascendência ucraniana na formação do traçado original da cidade de Roncador e em seu processo de expansão urbana. Nesse sentido, a figura 2 ilustra esse período 
A PRÁXIS DA CULTURA UCRANIANA NO ESPAÇO URBANO DE RONCADOR (PR), BRASIL: ANÁLISE DAS CATEGORIAS FORMA, FUNÇÃO, ESTRUTURA E PROCESSO

caracterizado pela colonização do município, evidenciando o desenvolvimento da região em meados da década de 1970, que já contava com a avenida principal, indicando, assim, o início do crescimento urbano e o avanço sobre a densa mata que cobria a área no período anterior ao seu povoamento e que acabou dando lugar ao traçado das ruas.

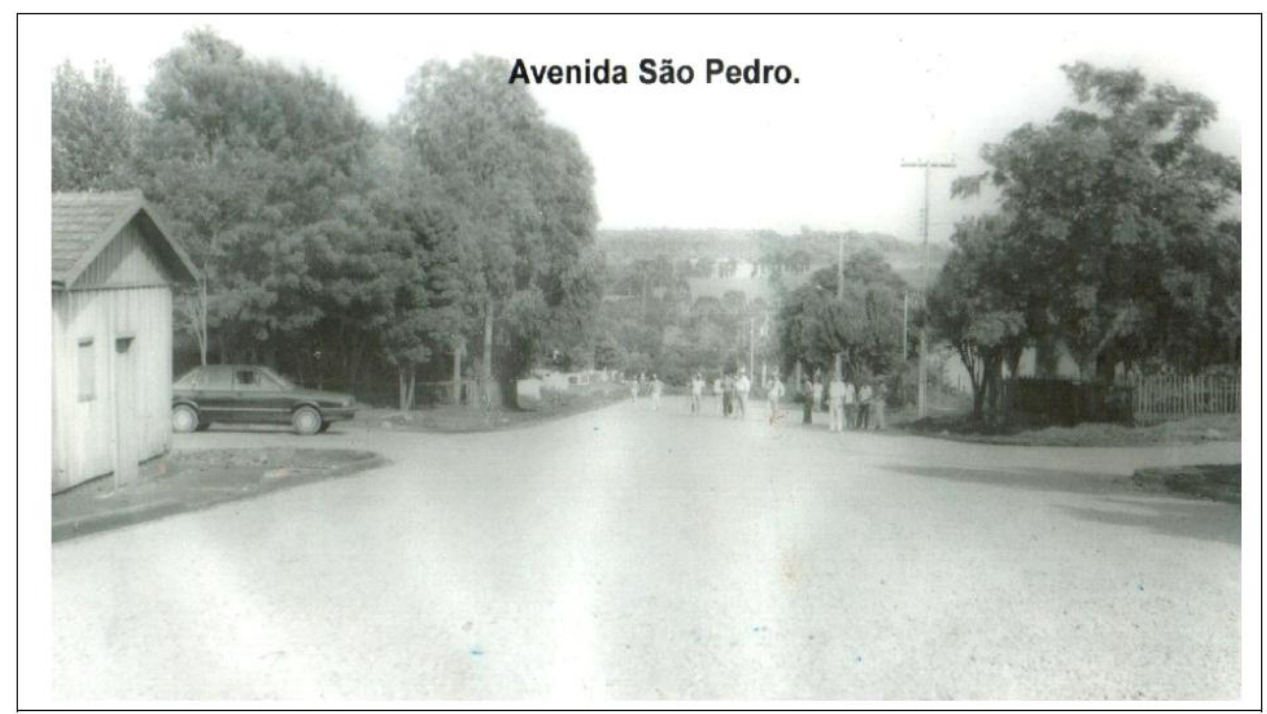

Figura 2: Avenida São Pedro de Roncador - PR [1975?]

Fonte: Acervo do Departamento de Cultura de Roncador.

Cabe ainda a ressalva de que, além dos descendentes de ucranianos, a população do município de Roncador também é formada por descendentes de poloneses, italianos e portugueses, assim como migrantes procedentes das regiões Sudeste e Nordeste do Brasil, que compõem, dessa maneira, a identidade étnica do município, cujas características culturais foram herdadas dos colonizadores que contribuíram na formação e no desenvolvimento regional.

\section{A CULTURA UCRANIANA NA IMAGEM DA CIDADE}

Ao estudar a cultura ucraniana no espaço urbano de Roncador, identificamos as formas arquitetônicas e culturais típicas dessa etnia, uma vez que se encontram impregnadas na paisagem da cidade e no cotidiano das famílias e são referenciais simbólicos da sociedade, que as identifica com o seu espaço e com o seu passado, conferindo identidade ao grupo e o seu reconhecimento como habitante do lugar. Assim, devemos entender que a cultura é um dos elementos 
organizadores do espaço urbano, da sociedade e das cidades, sendo que o espaço urbano representa o espaço da cidade dotado de inúmeras manifestações culturais humanas, expressas em suas paisagens (KIRCHHEIM, 2010). Dessa forma, a cidade é o lócus de distintas sociabilidades urbanas, onde convivem grupos de diferentes etnias que se encontram em contínua interação, flexibilizando seus hábitos e costumes tradicionais devido aos contatos interétnicos.

Cumpre esclarecer que, no decurso do desenvolvimento histórico, o processo de modernização e inovação da vida urbana tem constituído um desafio para a preservação do patrimônio cultural, forçando, dessa forma, o desaparecimento e/ou esquecimento das origens. Todavia, Souza (2008, p. 121) afirma que "é fundamental que se mantenha o sistema de referências, porque o homem sempre precisou dele para identificar-se com o meio, com os espaços, com a cidade. Trata-se da relação entre o lugar e o cidadão, que se vem enfraquecendo [...]". Nessa perspectiva, Silva (2004) assinala que a preservação, sobretudo quando envolve bens arquitetônicos e a cidade, continua a ser um desafio, haja vista que, segundo algumas interpretações, pode se constituir em um empecilho para a expansão urbana e até para o desenvolvimento econômico. A realidade urbana, porém, se apresenta em constante transformação e, desse modo, o tradicional e o moderno confrontam-se diariamente, uma vez que "o tempo atual, marcado pelas mudanças, transformações e destruições, contrasta com outros tempos: o das permanências, da continuidade e da memória" (JAREK, 2007, p. 185).

Assim sendo, salientamos, no presente estudo, as diversas formas deixadas pelo povo ucraniano e que expressam a materialidade cultural do grupo presente na paisagem urbana de Roncador, constituindo o arcabouço cultural que ajudou a construir a história e a identidade local. Destacamos a presença da arquitetura religiosa como um elemento de identificação e coesão social. Dessa forma, a Igreja Ucraniana, de rito oriental e estilo arquitetônico bizantino, inserida no espaço do atual município de Roncador no período de sua colonização, constitui a principal expressão da cultura ucraniana na cidade, sendo um componente de fundamental importância para a manutenção da cultura e de sua língua, uma vez que as tradições litúrgicas são realizadas no rito ucraniano, permitindo a preservação de seus hábitos e costumes religiosos. Portanto, entendemos que a prática religiosa 
A PRÁXIS DA CULTURA UCRANIANA NO ESPAÇO URBANO DE RONCADOR (PR), BRASIL: ANÁLISE DAS CATEGORIAS FORMA, FUNÇÃO, ESTRUTURA E PROCESSO

mantém-se como principal mecanismo de resistência e manutenção da cultura ucraniana na atualidade, o que confere destaque à religião como sustentáculo dessa cultura. A figura 3 mostra a Igreja São Nicolau do rito ucraíno-católico presente na imagem da cidade de Roncador, bem como o interior da Igreja com a presença de vários ícones.
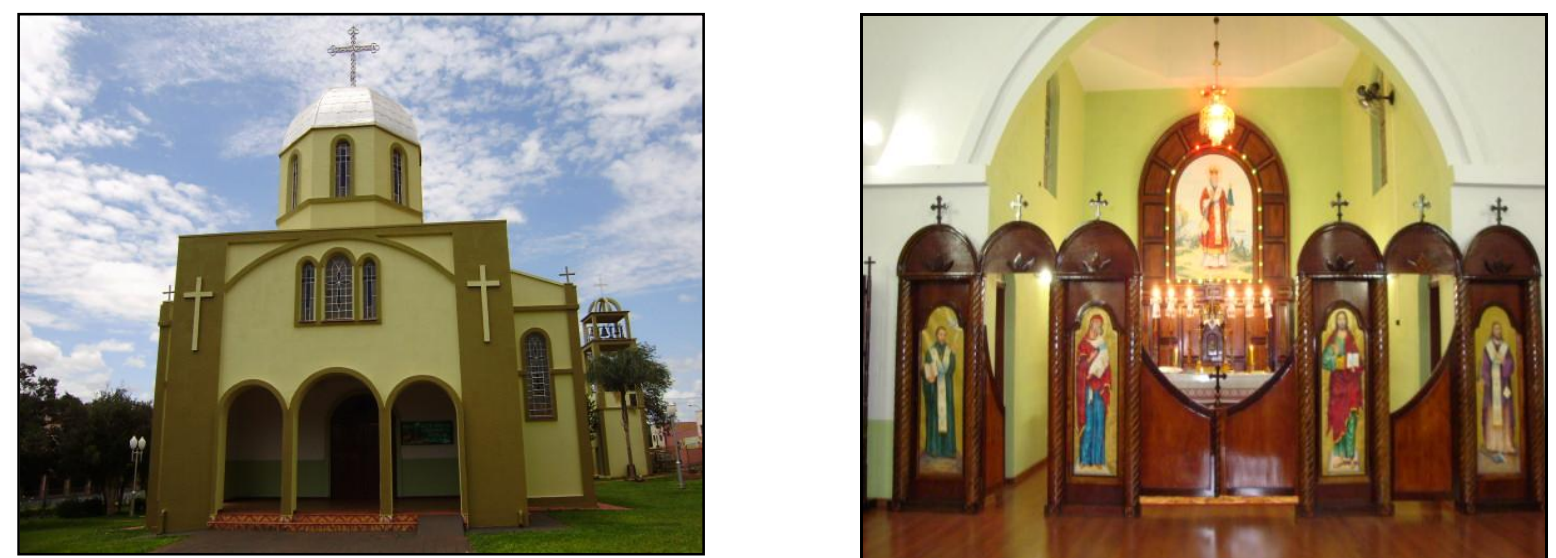

Figura 3: À esquerda: Paróquia do rito ucraniano São Nicolau no espaço urbano de Roncador; À direita: Santuário da Paróquia São Nicolau com destaque para os ícones.

Fonte: KALINOVSKI, Elaine C. Z. 05/04/2014.

Como podemos perceber na figura 3, a Igreja Ucraniana de Roncador é caracterizada pela presença de cúpulas em seu exterior, o que denota que a mesma foi construída seguindo o padrão arquitetônico bizantino que possui a cúpula como um dos seus principais elementos, sendo uma característica peculiar a todas as igrejas ucranianas de rito oriental. Cabe ressaltar que as igrejas ucranianas no Paraná foram construídas pelos primeiros imigrantes ucranianos que chegaram ao Brasil, uma vez que buscavam afirmar a identidade étnica ucraniana no novo território, bem como assegurar a preservação de suas manifestações religiosas através de suas igrejas. Essas igrejas, inicialmente construídas com madeira, que era retirada da vasta floresta que caracterizava a paisagem do território paranaense quando da chegada desses imigrantes, foram substituídas por construções de alvenaria, como podemos observar na figura acima.

Conforme Batista, Imaguire e Corrêa (2009, p. 84), ainda "na década de 1930 já ocorrem algumas transformações com relação à constituição da forma de construir ucraniana: nas paróquias mais importantes, já se passa a construir em alvenaria de tijolos autoportantes [...]". A Igreja Ucraniana São Nicolau de Roncador 
A PRÁXIS DA CULTURA UCRANIANA NO ESPAÇO URBANO DE RONCADOR (PR), BRASIL: ANÁLISE DAS CATEGORIAS FORMA, FUNÇÃO, ESTRUTURA E PROCESSO

foi construída entre os anos de 1939 e 1940 pelos primeiros colonos de ascendência ucraniana. Era de madeira e foi substituída por uma construção em alvenaria na década de 1970, sendo criada a então Paróquia São Nicolau, que possui duas cúpulas bizantinas, indicando a presença da etnia ucraniana no espaço urbano de Roncador, e devendo, assim, ser sempre possibilitado a visualização dessa edificação vultosa da cidade, que representa parte importante de seu patrimônio cultural e paisagístico, constituindo-se em uma peculiar representação da cultura do povo ucraniano nesse espaço.

Da mesma forma, convém salientar o padrão arquitetônico das casas construídas pelos primeiros colonos de origem ucraniana que chegaram à região que corresponde ao atual município de Roncador. As casas seguiam um estilo europeu, feitas de madeira, e destacavam-se por suas cores marcantes, de diferentes matizes, simbolizando a cultura ucraniana neste espaço geográfico, além de apresentarem grandes varandas, com belos ornamentos em seus beirais, que são tipicamente ucranianos. Na figura 4, podemos observar as características típicas das construções em estilo arquitetônico ucraniano, presentes na área urbana de Roncador na atualidade, ainda que em número reduzido.

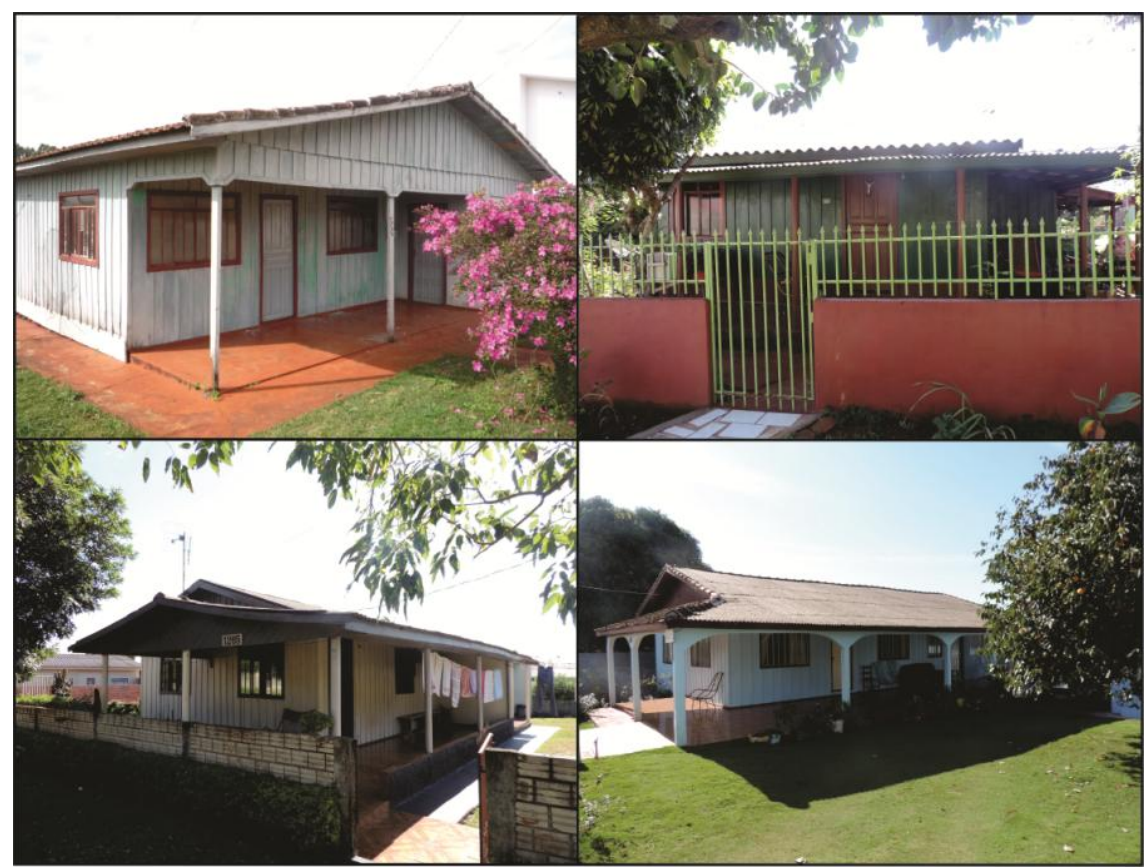

Figura 4: Residências com características típicas ucranianas no espaço urbano de Roncador.

Fonte: KALINOVSKI, Elaine C. Z. 05/04/2014. 
Não obstante, ressaltamos que, em face ao processo de urbanização capitalista, a difusão de uma cultura moderna e a falta de um adequado planejamento voltado para a preservação de origem tem contribuído para a sua descaracterização, e as formas tradicionais vêm cedendo lugar ao novo que se impõe, substituindo as casas feitas pelos colonos por casas modelos da cidade. Nesse sentido, Mayr (2008) assevera:

Assim, em relação às edificações da imigração, são atribuídas lembranças da tradição, terra, família, coisa antiga, simplicidade e colônia, que remetem à origem colonial dessas regiões. As casas modernas associam valores como comodidade, perfeição, luxo, novo, ser mais gente, à representação de um salto qualitativo no padrão de habitar (MAYR, 2008, p. 258).

Desse modo, percebemos que há uma rejeição do legado cultural dos antepassados, tanto pelos setores públicos quanto pelos membros mais jovens, descendentes de ucranianos, que buscam constantemente novos modelos de construções mais adequados ao atual processo marcado pela consolidação de novas estruturas modernizadoras, no cerne de uma sociedade capitalista permeada de interesses econômicos. Diante disso, a autora supracitada evidencia o estigma de ser "colono", sendo que: "Aos termos colono e colônia são atribuídas imagens tais como rudeza, ignorância, atraso e outras que são negativas quando confrontadas com a imagem da modernidade que é amplamente difundida pelos meios de comunicação" (MAYR, 2008, p. 258).

Assim, observamos que, devido às transformações vividas pela sociedade $e$ as próprias transformações do espaço no decorrer do processo histórico, houve a tendência ao abandono ou esquecimento de alguns traços e costumes culturais típicos ucranianos na área urbana de Roncador, sendo que o estilo arquitetônico das casas e das edificações já não é mais o mesmo de quando foram implantadas pelas primeiras famílias descentes de ucranianos que chegaram à localidade. Constatamos, portanto, que houve o favorecimento de estilos modernos. Todavia, ressalvamos que, embora a cultura ucraniana não esteja mais conservada em sua plenitude, ela vem permanecendo enquanto rugosidade, isto é, como formas remanescentes herdadas do passado, produzidas em outro contexto histórico, caracterizado por outras condições socioeconômicas e técnicas, e que se encontram 
presentes na imagem da cidade nos dias atuais, compondo o conjunto urbanístico e arquitetônico remanescente de períodos anteriores. Nesse sentido, com relação ao termo rugosidade, Santos (2008a) esclarece:

\begin{abstract}
Chamemos rugosidades ao que fica do passado como forma, espaço construído, paisagem, o que resta do processo de supressão, acumulação, superposição, com que as coisas se substituem e acumulam em todos os lugares. As rugosidades se apresentam como formas isoladas ou como arranjos. É dessa forma que elas são uma parte desse espaço. Ainda que sem tradução imediata, as rugosidades nos trazem os restos de divisões do trabalho já passadas (todas as escalas da divisão do trabalho), os restos dos tipos de capital utilizados e suas combinações técnicas e sociais com o trabalho (SANTOS, 2008a, p. 140).
\end{abstract}

Para elucidar o nosso entendimento, Godoy (2004), fazendo uma interpretação do conceito de rugosidades segundo a definição proposta por Milton Santos, pondera que as "rugosidades" são formas espaciais que foram produzidas no passado em momentos distintos do modo de produção, guardando, assim, características sócio-culturais específicas do momento em que foram produzidas, sendo que "A noção de 'rugosidades' complementa a concepção de que a produção do espaço é ao mesmo tempo, construção e destruição de formas e funções sociais dos lugares" (GODOY, 2004, p. 34).

Assim sendo, temos a proposta de analisar, neste artigo, como a cultura ucraniana vem permanecendo no espaço urbano de Roncador na atualidade, frente ao processo de modernização a que está sujeito o mundo urbano. Nesse sentido, partimos do pressuposto de que as formas tradicionais e costumes culturais da etnia ucraniana revelam sentimentos e simbolismos do grupo, sendo, assim, um fator de permanência e da existência de rugosidades. Percebemos, no decorrer da pesquisa, que a cultura ucraniana possui um padrão arquitetônico das edificações, tradições, costumes, e uma forma de vida peculiar, estando fortemente arraigadas no cotidiano de seus descendentes, principalmente entre aqueles mais idosos e de meia idade, que procuram assegurar a preservação de seus traços culturais típicos para a manutenção de sua identidade, oferecendo resistência às inovações. Dessa forma, a modernidade encontra o obstáculo das heranças, dos resquícios das formas tradicionais, cristalizados no espaço e na sociedade. 
As famílias migrantes de ascendência ucraniana colonizaram as terras de Roncador e proporcionaram o destaque de sua cultura neste espaço, impregnando-o com suas formas culturais, que convivem concomitantemente com o novo que surge. É dessa maneira que entendemos o espaço como um mosaico repleto de formas pretéritas e formas atuais. Portanto, o espaço combina o novo, fruto das inovações, com o velho, que resiste às mudanças e permanece oferecendo resistência à modernização. Conforme salienta Santos:

Cada lugar combina variáveis de tempos diferentes. Não existe um lugar onde tudo seja novo ou onde tudo seja velho. A situação é uma combinação de elementos com idades diferentes. $O$ arranjo de um lugar, através da aceitação ou rejeição do novo, vai depender da ação dos fatores de organização existentes nesse lugar, quais sejam, o espaço, a política, a economia, o social, o cultural... (SANTOS, 2008b, p. 106).

Ademais, é importante ressaltar que a mudança de processos não implica necessariamente o rompimento com as antigas formas espaciais, uma vez que "[...] o espaço é uma forma, uma forma durável, que não se desfaz paralelamente à mudança de processos; ao contrário, alguns processos se adaptam às formas preexistentes enquanto que outros criam novas formas para se inserir dentro delas" (SANTOS, 1980, p. 138).

Isto posto, salientamos que a cultura ucraniana vem permanecendo e resistindo ao processo de urbanização de Roncador, existindo remanescentes dos traços originais que, no atual momento histórico, são interpretados por nós como rugosidades, pois refletem um tempo que não mais existe. Porém, tais remanescentes ainda compõem o espaço enquanto formas cristalizadas, das quais, ressaltamos a importância de sua conservação, de forma que não venham a ser extintas pela expansão do modo de produção capitalista dominante e pelos novos fenômenos da urbanização que destroem as características originais. Diante disso, esta pesquisa levanta lacunas para a questão do apoio público municipal na preservação da cultura ucraniana no espaço urbano de Roncador, não pelo fato de simplesmente preservar a identidade étnica ucraniana, mas a própria identidade do município, que foi construída sob forte influência dessa cultura. Assim, ressalvamos que a cultura do povo ucraniano pode ser identificada na imagem urbana de Roncador. Ferrara (2008) entende que 
A imagem corresponde à informação solidamente relacionada com um significado que se constrói numa síntese de contornos claros que a faz única e intransferível. [...] É um código urbano e impõe uma leitura e fruição que estão claramente inscritos na cidade como espaço construído (FERRARA 2008, p. 194).

Dessa forma, estando à cultura ucraniana presente na imagem da cidade, podendo ser identificada através de sua arquitetura, bem como de suas demais manifestações culturais e religiosas, pode se constituir em um importante atrativo turístico para descendentes e apreciadores dessa cultura com tradições milenares. Por conseguinte, a imagem urbana também é apelativa, conforme mostra a autora acima citada: "Apelativa, a imagem urbana é um cartão postal, é uma espécie de publicidade que concretiza o modo de reconhecer e avaliar uma cidade; é o registro temático preferido dos cartões e mapas turísticos e faz as delícias de qualquer viajante mais desavisado" (FERRARA, 2008, p. 196). Destarte, os traços culturais impressos pelo povo ucraniano na paisagem da cidade, além de identificar o grupo ucraniano no espaço roncadorense, pode, inclusive, estimular o turismo regional e favorecer o próprio desenvolvimento local, atraindo visitantes de outros locais para conhecer a peculiaridade cultural da cidade de Roncador, atraídos pela riqueza da cultura ucraniana, no que diz respeito à arquitetura de suas edificações, costumes, tradições, religiosidade, culinária e língua, cujo legado cultural se faz presente na imagem da cidade e representa um relevante potencial turístico.

Nesse caso, julgamos pertinente a discussão e elaboração de um planejamento urbano voltado para a preservação cultural, como instrumento que assegure a manutenção dos resquícios culturais da etnia ucraniana presentes na área urbana de Roncador, alertando-se sobre os riscos de um crescimento desordenado da cidade e os usos modernos e de outras culturas em detrimento dos usos tradicionais da cultura local, de forma que o avanço da cidade não venha a negligenciar os aspectos culturais, principalmente os aspectos da cultura ucraniana, assegurando a preservação do patrimônio histórico-cultural e paisagístico de Roncador. Assim, corroborando nossa perspectiva, Lubachevski e Sahr (2005, p. 26) afirmam que "O planejamento urbano pode se tornar um mecanismo de preservação 
da cultura, sobretudo, de suas manifestações mais visíveis, como as edificações e monumentos".

Chamamos a atenção do poder público municipal para a elaboração de políticas públicas consistentes, voltadas para a conservação dos marcos culturais do espaço urbano de Roncador, assegurando a preservação de sua imagem urbana, de forma que a mesma traga sempre a marca da cultura ucraniana. Para tanto, salientamos que deve haver a preocupação pela preservação no interior do próprio grupo, pressionando aqueles que pensam e interferem no planejamento a não destruírem as suas origens, mas atuarem no sentido de preservá-las e resgatá-las, haja vista o seu valor histórico e cultural para a cidade, além de sua relevância econômica, como potencial de desenvolvimento local.

\section{CONSIDERAÇÕES FINAIS}

Com base no levantamento de dados realizado em nosso estudo, consideramos que a população de ascendência ucraniana participou ativamente do processo de colonização e urbanização do município de Roncador, inserindo os seus traços culturais típicos neste espaço geográfico, sendo hoje a principal influência cultural da cidade. Nesse sentido, cumpre elucidar que a cultura do povo ucraniano tem se constituído em um elemento de organização do espaço urbano do município estudado, visto que os seus elementos culturais são referenciais simbólicos da cidade e da sociedade, e configuram um espaço étnico-cultural de representatividade, que tem como elemento majoritário o descendente da etnia ucraniana que migrou para a região em estudo no período histórico de sua colonização, colaborando para a construção de uma identidade local e para o desenvolvimento regional.

Diante dessas assertivas, procuramos evidenciar a materialidade cultural impressa pelo grupo ucraniano na área urbana de Roncador, e que compõe a manifestação espacial desta cultura visível na imagem da cidade, podendo ser apreendida através da arquitetura de suas edificações, como a igreja e as casas em estilo ucraniano que constituem parte importante do patrimônio históricoarquitetônico e urbano da área delimitada em nosso estudo e, dessa forma, devem 
ser alvo das políticas públicas voltadas para a preservação e restauração do patrimônio cultural urbano.

Salientamos que tais formas culturais, impregnadas no interior de uma estrutura caracterizada pelo processo de colonização da região, subsistiram ao processo de modernização do contexto urbano, impulsionado pelas novas dinâmicas impostas pela urbanização moderna. Não obstante, face às transformações que ocorreram no decorrer do tempo histórico e a miscigenação cultural, verificamos que houve a descaracterização das velhas formas culturais e, diante disso, a cultura ucraniana não se encontra mais preservada em sua integridade, existindo atualmente remanescentes dos traços originais herdados dos antepassados que colonizaram o município, e que são entendidos por nós como rugosidades. Assim sendo, evidenciamos que o atual cenário entrelaçado aos processos inovadores da vida urbana, marcado pela consolidação de novos modelos mais adequados às novas realidades da sociedade capitalista contemporânea, convive simultaneamente com as formas pretéritas que ainda compõem o espaço.

Nessa perspectiva, percebemos com esta pesquisa que as formas tradicionais da etnia ucraniana vêm fazendo-se presentes em espaços e tempos contemporâneos caracterizados por outras dinâmicas, diferentes das que lhes deram origem, haja vista o valor simbólico e cultural que representam no cotidiano das famílias descendentes de imigrantes ucranianos, principalmente entre a parcela mais idosa e adulta da população, que procura reproduzir as suas tradições culturais e o seu modo de vida para as gerações vindouras, assegurando, assim, a manutenção das características culturais que identificam o grupo com as mesmas afinidades étnico-culturais.

Portanto, como análise final deste artigo ressaltamos a importância da preservação das manifestações da cultura ucraniana no espaço urbano de Roncador, principalmente no que diz respeito às formas materiais da cultura que se encontram presentes na imagem da cidade. Consideramos que o poder público municipal pode contribuir para a permanência e o resgate histórico-cultural, através de um planejamento urbano voltado para a preservação de origem, mantendo e reproduzindo os traços e as manifestações culturais típicas ucranianas na cidade, como fator de identificação e potencialidade para o desenvolvimento municipal, uma 
A PRÁXIS DA CULTURA UCRANIANA NO ESPAÇO URBANO DE RONCADOR (PR), BRASIL: ANÁLISE DAS CATEGORIAS FORMA, FUNÇÃO, ESTRUTURA E PROCESSO

vez que a recuperação e conservação das rugosidades da cultura ucraniana no meio urbano de Roncador pode se constituir em um relevante potencial para 0 desenvolvimento de atividades turísticas, além de assegurar e reforçar a identidade do grupo ucraniano na região.

\section{REFERÊNCIAS BIBLIOGRÁFICAS}

BAGNO, M. Preconceito lingüístico: o que é, como se faz. 34. ed. São Paulo: Loyola, 2004.

BATISTA, F.D.; IMAGUIRE, M.R.G.; CORRÊA, S.R.M. Igrejas Ucranianas: Arquitetura da Imigração no Paraná. Curitiba: Instituto Arquibrasil, 2009.

CARNEIRO, J.A. História Oral como instrumento no desenvolvimento e elaboração da pesquisa. In: Boletim de Geografia. Maringá, v. 30, n. 2, p. 121-131, 2012.

CLAVAL, P. "A volta do cultural" na Geografia. In: Mercator - Revista de Geografia da UFC, v. 1, n. 1, 2002.

Reflexões sobre a Geografia Cultural no Brasil. In: Espaço e Cultura, UERJ. Rio de Janeiro, n. 8, p. 7-29, 1999.

CORRÊA, R.L. O espaço urbano. 2. ed. São Paulo: Ática, 1999.

FERRARA, L.D.A. Cidade: imagem e imaginário. In: SOUZA, C.F.; PESAVENTO, S.J. (Orgs.). Imagens urbanas: os diversos olhares na formação do imaginário urbano. 2. ed. Porto Alegre: UFRGS, p. 193-201, 2008.

FERREIRA, J.C.V. Municípios paranaenses: origens e significados de seus nomes. Curitiba: Secretaria de Estado da Cultura, 2006.

GODOY, P. Uma reflexão sobre a produção do espaço. In: Estudos Geográficos, Rio Claro, n. 2, p. 29-42, jun. 2004.

HISTÓRICO DO MUNICÍPIO DE RONCADOR. História, pioneiros e atualidades. Roncador: Prefeitura Municipal de Roncador, 1986.

IBGE, Instituto Brasileiro de Geografia e Estatística. Pesquisa de dados básicos: Roncador - 2010.2 Pr. Disponível em: <http://www.ibge.gov.br/cidadesat/topwindow.htm?1>. Acesso em: 23 jun. 2011. 
A PRÁXIS DA CULTURA UCRANIANA NO ESPAÇO URBANO DE RONCADOR (PR), BRASIL: ANÁLISE DAS CATEGORIAS FORMA, FUNÇÃO, ESTRUTURA E PROCESSO

IPARDES, Instituto Paranaense de Desenvolvimento Econômico e Social. Caderno estatístico município de Roncador. 2011. Disponível em: $<$ http://www.ipardes.gov.br/cadernos/Montapdf.php?Municipio=87320\&btOk=0k>. Acesso em: 23 jun. 2011.

JAREK, G.L.S. Cidades, culturas, memórias e identidades: uma proposta em educação patrimonial. In: Ágora, Santa Cruz do Sul, v. 13, n. 2, p. 180-191, jul./dez. 2007.

KALINOVSKI, E.C.Z.; BOVO, M.C.; TÖWS, R.L. Análise da permanência da práxis da cultura ucraniana no espaço urbano de Roncador-PR. In: Revista Geomae. Campo Mourão: Editora da Fecilcam, v. 2, n. e. 1, p. 171-189, 2011.

KIRCHHEIM, C.A.S. Uma leitura da paisagem urbana e a migração em Marechal Cândido Rondon/Pr. 2010. 131 f. Dissertação (Mestrado) - Universidade Estadual de Maringá, Maringá, 2010.

LUBACHEVSKI, J.; SAHR, C.L.L. A semiótica na análise dos marcos referenciais, do planejamento urbano e da cultura ucraniana: o caso de Prudentópolis - Pr. In: UEPG, Ponta Grossa, n. 13, p. 25-34, jun. 2005.

MAYR, A.A.D.A. Um olhar nas áreas de imigração germânica: algumas considerações. In: SOUZA, C.F.; PESAVENTO, S.J. (Orgs.). Imagens urbanas: os diversos olhares na formação do imaginário urbano. 2. ed. Porto Alegre: UFRGS, p. 251-261, 2008.

MEIHY, J.C.S.B. Manual de história oral. São Paulo: Loyola, 1996.

MELLO, J.B.F. Símbolos dos lugares, dos espaços e dos "deslugares". In: Espaço e Cultura, UERJ. Rio de Janeiro, edição comemorativa, p. 167-174, 2008.

PERIÓdICO SUPLEMENTO DO JORNAL PRÁCIA. Missionário Ucraniano no Brasil. Prudentópolis: [s/ed], Boletim da paróquia São Nicolau de Roncador, publicado pelos padres da Ordem de São Basílio Magno. 2006.

SALKOVSKI, Pe. Varcilio Basil. [Entrevista concedida em dezembro de 2011]. Roncador, 2011.

SANTOS, M. A natureza do espaço: técnica e tempo, razão e emoção. 4. ed. São Paulo: Editora da Universidade de São Paulo, 2008a.

A urbanização brasileira. São Paulo: Hucitec, 1993. 
Espaço \& Método. São Paulo: Nobel, 1985.

. Espaço e Sociedade. Petrópolis: Vozes, 1980.

Metamorfoses do Espaço Habitado: Fundamentos Teóricos e Metodológicos da Geografia. São Paulo: Editora da Universidade de São Paulo, 2008b.

SILVA, M.G.L. Cidades turísticas: identidades e cenários de lazer. São Paulo: Aleph, 2004.

SLOBODJAN, E. [Entrevista concedida em janeiro de 2012]. Roncador, 2012.

SOUZA, C.F. Construindo o espaço da representação: ou o urbanismo de representação. In: SOUZA, C.F.; PESAVENTO, S.J. (Orgs.). Imagens urbanas: os diversos olhares na formação do imaginário urbano. 2. ed. Porto Alegre: UFRGS, p. 107-122, 2008.

THOMPSON, P. A voz do passado: história oral. 2. ed. Rio de Janeiro: Paz e Terra, 1998.

YURKIW, E.; HARACENKO, A.A.S. A influência da cultura do povo ucraniano no processo de colonização do município de Roncador- PR. In: Boletim de Geografia, Maringá, v. 30, n. 1, p. 147-162, 2012.

YURKIW, E. Colonização do município de Roncador-Pr: A organização do espaço geográfico mediante a práxis da cultura ucraniana. 2009. (Monografia) - Faculdade Estadual de Ciências e Letras de Campo Mourão, Campo Mourão, 2009. 